\title{
Development and characterization of a new inbred transgenic rat strain expressing DsRed monomeric fluorescent protein
}

\author{
Sonia Montanari $\cdot$ Xing-Hua Wang · Gustavo Yannarelli • \\ Victor Dayan · Thorsten Berger • Larissa Zocche • \\ Eiji Kobayashi - Sowmya Viswanathan - Armand Keating
}

Received: 15 September 2013/ Accepted: 30 June 2014

(C) Springer International Publishing Switzerland 2014

\begin{abstract}
The inbred rat is a suitable model for studying human disease and because of its larger size is more amenable to complex surgical manipulation than the mouse. While the rodent fulfills many of the criteria for transplantation research, an important requirement is the ability to mark and track donors cells and assess organ viability. However, tracking ability is limited by the availability of transgenic ( $\mathrm{Tg})$ rats that express suitable luminescent or fluorescent proteins. Red fluorescent protein cloned from Discosoma coral (DsRed) has several advantages over other fluorescent proteins, including in vivo detection in the whole animal and ex vivo visualization in organs as there is no interference with autofluorescence. We generated and characterized a novel inbred $\mathrm{Tg}$ Lewis
\end{abstract}

Electronic supplementary material The online version of this article (doi:10.1007/s11248-014-9814-z) contains supplementary material, which is available to authorized users.

S. Montanari - X.-H. Wang · G. Yannarelli ·

V. Dayan - L. Zocche $\cdot$ S. Viswanathan $\cdot$ A. Keating

Cell Therapy Program, Princess Margaret Hospital,

University Health Network, Toronto, ON, Canada

S. Montanari · A. Keating

Institute of Medical Science, University of Toronto,

Toronto, ON, Canada

S. Montanari $(\bowtie)$

Orsino Cell Therapy Translational Research Laboratory,

Princess Margaret Cancer Centre, 610 University Avenue,

Room 5-303, Toronto, ON M5G 2M9, Canada

e-mail: montanari.sonia@gmail.com rat strain expressing DsRed monomeric (DsRed mono) fluorescent protein under the control of a ubiquitously expressed ROSA26 promoter. DsRed mono $\mathrm{Tg}$ rats ubiquitously expressed the marker gene as detected by RT-PCR but the protein was expressed at varying levels in different organs. Conventional skin grafting experiments showed acceptance of DsRed monomeric Tg rat skin on wild-type rats for more than 30 days. Cardiac transplantation of DsRed monomeric $\mathrm{Tg}$ rat hearts into wild-type recipients further showed graft acceptance and long-term organ viability ( $>6$ months). The DsRed monomeric Tg rat provides marked cells and/or organs that can be followed for long periods without immune rejection and therefore is a suitable model to investigate cell tracking and organ transplantation.

\footnotetext{
T. Berger

The Campbell Family Institute for Breast Cancer Research, University Health Network, Toronto, ON, Canada

E. Kobayashi

Divisions of Organ Replacement Research and Animal Resource Project, Centre for Molecular Medicine, Jichi Medical School, Tochigi, Japan
} 
Keywords Bone marrow mesenchymal stromal cells · DsRed monomeric protein · Heterotopic heart transplantation · Immunogenicity · Skin grafting · Transgenic rat

\begin{tabular}{ll}
\multicolumn{2}{l}{ Abbreviations } \\
BM-MSCs & Bone marrow-mesenchymal stromal \\
& cells \\
HHT & Heterotopic heart transplantation \\
LEW & Lewis \\
Mono & Monomeric \\
MRI & Magnetic resonance imaging \\
RFP & Red fluorescent protein \\
Tg & Transgenic
\end{tabular}

\section{Introduction}

Progress in cell, tissue and organ transplantation has been facilitated by improvements in marking and tracking implanted cells in animal models (Hara et al. 2008; Hung et al. 2010). Fluorescent dyes and molecular tags such as green fluorescent protein from the jellyfish Aequorea victoria (Hakamata et al. 2001; Remy et al. 2010), luciferase from the firefly Photinus pyralis (Conradi et al. 2011; Hakamata et al. 2006) and red fluorescent protein from the Discosoma coral have been widely used for such purposes (Filipiak and Saunders 2006; Gama Sosa et al. 2010).

Transgenic (Tg) animals expressing fluorescent dyes (Murakami and Kobayashi 2005) enable threedimensional study of the location, motility, adhesion, and interactions of individual cells transplanted into hosts with a normal background (Mothe et al. 2005).

Inbred rat models are an important component of pre-clinical studies, in part because of their larger size compared with mice $(10 \times)$ (Mashimo and Serikawa 2009; Cozzi et al. 2008). Inbred rats are established by mating male and female littermates for 20 or more consecutive generations thereby giving a relatively homogeneous genetic background, which is often a critical prerequisite for syngeneic organ and cell transplantation studies (Doyle et al. 2012; Inoue et al. 2005).

Over the last decade, several color-engineered $\mathrm{Tg}$ rats have been generated from different strains [Wistar, Dark Agouty and Lewis (LEW)] carrying different cell-tracking proteins (GFP, LacZ, DsRed2 and
Luciferase) (Murakami and Kobayashi 2012; Sato et al. 2003) including animals with dual markers to enable visualization of cell fate by both fluorescence and luminescence (Sato et al. 2004). Although these models enable transplanted cells to be identified, most are immunogenic and lead to rejection in a few days (Goulding et al. 2008). Consequently, the ability to undertake long-term analysis of labeled cells derived from $\mathrm{Tg}$ animals from the same strain that express high levels of the transgene while maintaining low levels of immunogenicity is limited (Moloney et al. 2010; Pan et al. 2009).

In the present study, we generated and characterized a novel inbred LEW Tg rat expressing monomeric red (DsRed mono) fluorescent protein under the control of the ubiquitous promoter, ROSA26.

Like GFP, DsRed monomeric protein (Shaner et al. 2005; Campbell et al. 2002) is a fluorescent protein that requires no chemical substrate for visualization (Garcia-Parajo et al. 2001; Strack et al. 2008). DsRed monomer is a naturally occurring red fluorescent protein mutant of a coral of the genus Discosoma and is used as a gene-based reporter (Bevis and Glick 2002).

DsRed shares only $26 \%$ amino acid sequence homology with GFP, and a number of mutagenesis studies have shown improved physical and spectral features (Wall et al. 2000). The DsRed monomer (mono), with a total of 45 amino acid substitutions in native DsRed has improved fluorescence characteristics without any toxic oligomerization. Specifically, DsRed mono demonstrates resistance to photobleaching (fourfold-five fold greater than that of GFP), $\mathrm{pH}$ insensitivity and stable conformation (Baird et al. 2000).

DsRed mono is spectrally distinct from GFP, thereby enabling the two to be distinguished. Most GFP antibodies do not cross react with DsRed or its derivatives; the converse is also true (Strack et al. 2009).

GFP and its blue, cyan, and yellow variants have found widespread use as donor-acceptor pairs for fluorescence resonance energy transfer (FRET). Extending the spectrum of available colors to red wavelengths increases this applicability and provides a new FRET donor-acceptor alternative.

The DsRed mono is superior to the previously described DsRed tetramer as it does not aggregate (Verkhusha et al. 2001), and does not have slow or 
incomplete maturation and oligomeric states (Wall et al. 2000). We showed that the DsRed mono Tg rat displayed high levels of DsRed expression in most tissues and cells, including mesenchymal stromal cells (MSCs) that have been poorly characterized in previous Tg models.

We evaluated the immunogenic potential of DsRed mono protein in LEW wild-type recipients by performing skin grafting and heterotopic heart transplantation with ROSA26-DsRed monomer-LEW Tg rat donor cells. The heart transplant model was used to assess long-term viability and function of the donor organ.

\section{Materials and methods}

Generation of transgenic rats

An inbred rat strain, LEW (MHC haplotype: RT1 ${ }^{1}$ ), was purchased from Charles River Japan, Incorporate (Yokohama, Japan).

To generate ROSA26-DsRed monomer-LEW Tg rats, a standard microinjection technique was used as described previously (Menoret et al. 2010). Briefly, the SacI and NotI fragment (DsRed monomer cDNA) from a pDsRed-Monomer plasmid (Clontech, Palo Alto, CA) was inserted into the SacI and NotI sites of pBluescript II SK $(+)$ plasmid (Stratagene, La Jolla, CA), generating pBluescript II SK(+)-DsRedM. The SalI fragment of pBluescript II SK(+)-DsRedM was subsequently inserted into the pBROAD2 expression plasmid (InvivoGen, San Diego, CA) containing human ROSA26 promoter (Zambrowicz et al. 1997), and the PacI fragment containing the promoter and coding sequence was injected into the fertilized LEW rat egg.

The ROSA26-DsRed monomer-LEW Tg rats (specifically one male 8 weeks-old and one female 8 weeks-old rat) generated were transferred to the Ontario Cancer Institute (OCI)/Princess Margaret Hospital (PMH) in Toronto, Ontario, Canada according to the Material Transfer Agreement (MTA) number 2009-0594 and a colony was established.

ROSA26-DsRed monomer-LEW Tg rats were maintained in the hemizygous state. All experiments were performed in accordance with the Jichi Medical School Guide for Laboratory Animals (Japan) and in compliance with the Guidelines set by the Canadian
Council on Animal Care (CCAC) and University Health Network Institutional Guidelines (Canada).

Animals and housing

Wild-type LEW and ROSA26-DsRed monomer-LEW Tg rats were housed ( 2 rats per cage) with unlimited access to food and water. All procedures were approved by the University Health Network Institutional Guidelines (Canada) and Animal Use Protocol number 1489.

Reverse transcription polymerase chain reaction (RT-PCR)

Total RNA was extracted from organ samples (heart, spleen, liver, kidney and lung) obtained from ROSA26-DsRed monomer-LEW Tg rats $\left(\mathrm{RT}^{1}{ }^{1}\right)$ and wild-type LEW rats (RT1 ${ }^{1}$ ) (Charles River, USA) using Trizol reagent (Cerkovnik et al. 2007). One microgram of genomic DNA-free total RNA was reverse-transcribed using a High-Capacity cDNA Reverse Trascription Kit from Applied Biosystems (Cat\# 4368814).

GAPDH was used as the endogenous housekeeping gene to normalize the mRNA levels. The primer sequences for GAPDH were: 5'-TAGGGCTGG AAAATCACTGG-3' (forward) and 5'-GTATTCA TCACCCCCACCAC- $3^{\prime}$ (reverse). To evaluate the DsRed mono mRNA copy, the forward and reverse primer sequences used were (fwd: 5'-AGTTCC AGTACGGCTCCAAG-3') and (rev: 5'-AGATCT CGCCCTTCAGCAC-3'), respectively. Three hundred nanograms of cDNA were used for PCR using the conditions previously described.

DNA analysis

Genomic DNA was extracted from organ samples (heart, spleen, liver, kidney and lung) and tail samples of 21 days-old $\mathrm{Tg}$ rats (for genotyping procedures) by using a standard protocol. To screen for Tg rats we used the DsRed Sequence. (fwd: 5'-AGTTCCAGTA CGGCTCCAAG- $3^{\prime}$ ) and (rev: 5'-AGATCTCG CCCTTCAGCAC- $3^{\prime}$ ) were used as the forward and reverse primers, respectively (Invitrogen). Polymerase chain reaction (PCR) was performed in 35 cycles with a final volume of $25 \mu$ containing $500 \mathrm{ng}$ of genomic DNA, primer pairs (5 pM, $0.2 \mathrm{mM})$, dNTPs $(2 \mathrm{mM})$, 
$\mathrm{MgCl}_{2}(1.5 \mathrm{mM})$ and PCR reagents including Taq polymerase (Cat\# 10342-020, Invitrogen). Each cycle consisted of denaturation for $15 \mathrm{~s}$ at $94{ }^{\circ} \mathrm{C}$, primer annealing for $30 \mathrm{~s}$ at $56{ }^{\circ} \mathrm{C}$, and polymerization for $30 \mathrm{~s}$ at $72{ }^{\circ} \mathrm{C}$. The PCR products were electrophoresed through $1.5 \%$ agarose gel, stained with ethidium bromide, and photographed under UV light. The 294 bp-band was detected only in the Tg rat presenting the DsRed mono DNA sequence.

\section{Western blotting}

To detect the DsRed mono protein, organs from ROSA26-DsRed monomer-LEW Tg rat/wild-type LEW rat $\left(\mathrm{RT}^{1}{ }^{1}\right)$ and DsRed mono Mesenchymal Stromal Cells were used.

Organs such as heart, lung, kidney, liver and spleen were harvested from female rats, age 6-8 weeks, and protein lysates were obtained by crushing them after washing in sterile PBS, with a pestle under liquid nitrogen. Organ pieces were placed in a tube containing $1 \mathrm{ml}$ of Ripa protein lysis buffer (Mbiotech, MBI-21308, $50 \mathrm{mM}$ Tris- $\mathrm{HCl}$, pH 7.5, containing $105 \mathrm{mM} \mathrm{NaCl}$, $1 \%$ NP-40, $1 \%$ sodium deoxycholate, $0.1 \%$ SDS and 2 mM EDTA) plus protease inhibitors (complete, Mini, protease inhibitor cocktail tablets, \#11836153001, Roche) pipetting frequently on ice for $30 \mathrm{~min}$.

Confluent cells at passage 4 were detached using $0.25 \%$ trypsin. The trypsin was neutralized with DMEM $10 \%$ FBS, and the cells washed with ice cold PBS. The PBS was then discarded and the cell pellet placed on ice. $100 \mu$ of ice cold Ripa lysis buffer + protease inhibitors was added to the cell pellets, pipetting frequently for $30 \mathrm{~min}$ on ice. Protein lysates from organs and cells centrifuged at $4{ }^{\circ} \mathrm{C}$ for $20 \mathrm{~min}$ at $12,000 \mathrm{rpm}$ and the protein in the supernatant was collected. The protein concentration in the lysate was measured using Bradford assay. Briefly $2 \mu \mathrm{l}$ of each protein sample was added to $200 \mu \mathrm{l}$ Bradford solution (Bio-Rad Protein Assay\# 500-0006) (diluted 1:5 in $\mathrm{dH} 2 \mathrm{O}$ ) placed in a well of 96 well-plate in triplicates. BSA standards were used ranging from 0.25 to $2 \%$. The absorbance was measured at $595 \mathrm{~nm}$ in plate reader machine (SPECTRA MAX M5 ROM v2.1) and protein concentration determined from the curve of absorbance. Protein samples were solubilized and denatured by boiling in SDS and b-mercaptoethanol for $5 \mathrm{~min}$. Twenty micrograms of each protein were applied to a $12 \%$ polyacrylamide gel and electrophoresed for $20 \min$ at $50 \mathrm{~V}, 40 \min$ a $100 \mathrm{~V}$, $5 \mathrm{~min}$ a $120 \mathrm{~V}$. The protein was then transferred to nitrocellulose membranes. After blocking with $5 \%$ non-fat dry milk for $1 \mathrm{~h}$, the membranes were incubated overnight with the RFP/DsRed polyclonal Antibody (Cat\# PM005, MBL, International Corporation, USA) at dilution 1:1,000. HRP-conjugated goat-anti-rabbit IgG (Cell Signaling Technology, New England Biolabs, Canada; Cat\# 7074, dilution $1: 2,000)$ served as the secondary antibody. The membranes were briefly incubated with ECL detection reagent (ECL, Quebec, Canada) to visualize the proteins and then exposed with $\mathrm{x}$-ray films in the darkroom. $\beta$-Actin (Cell Signaling Technology, New England Biolabs, Canada; Cat\# 4967, dilution $1: 3,000)$ served as the internal control.

In vivo and ex vivo spectral fluorescence analysis

Spectral fluorescence images were obtained using the Maestro $^{\text {TM }}$ in-Vivo Imaging System (CRi, Inc., Woburn, MA) at CoreII, STTARR Facility (University Health Network, Toronto) A band-pass filter appropriate for the fluorochrome of interest (DsRed; $\mathrm{E}_{\mathrm{x}} 558 \mathrm{~nm}, \mathrm{E}_{\mathrm{m}} 583$ longpass filter; acquisition settings 500-950) was used for excitation and emission light, respectively. The tunable filter was stepped automatically in 10-nm increments while the camera captured images at an automatic exposure. To evaluate signal intensities, regions of interest (ROI) were selected over the background (mesh) areas, and the total fluorescence signal from those areas was determined. Total signal in the ROI in photons measured at the surface of the mesh was divided by the area of the mesh (in pixels) as well as the exposure time (in ms). The spectral fluorescent images consisting of autofluorescence spectra and DsRed fluorescent protein were captured and unmixed on the basis of their spectral patterns using commercially available software (Maestro; CRi). Spectral libraries were generated by assigning peaks to the background fluorescence, background from the imaging stage and plate, and fluorescence from DsRed mono rats or tissues. Spectral fluorescence images were obtained from 5 daysold ROSA26-DsRed monomer-LEW Tg rats (RT1 ${ }^{1}$ ) (whole body and organs) compared to wild-type LEW rats (whole body and organs). Spectral fluorescence images on the rat back were also obtained at 1, 2, 3, 4 weeks post skin graft. 
Immunohistochemistry colorimetric assay

Formalin-fixed, paraffin-embedded tissue blocks were sectioned to $5 \mu \mathrm{m}$, mounted on charged glass slides (Superfrost Plus, Fisher Scientific) and baked overnight at $60{ }^{\circ} \mathrm{C}$. The slides were deparaffinized with xylene, rehydrated through graded alcohols, and antigen retrieval was performed in a decloaking chamber by heating the slides to $98{ }^{\circ} \mathrm{C}$ for $20 \mathrm{~min}$ using $10 \mathrm{mM}$ Sodium Citrate buffer. Immunohistochemical reaction was performed using the avidinbiotin-complex method (ABC). Incubation was carried out with a rabbit polyclonal to RFP (Biotin) from Abcam (Abcam Inc., ON, Canada; Cat\# ab34771) followed by a biotinylated link antibody (Vector Laboratories, Burlingame, CA; Cat\# BA-1000) and then the ABC-Elite Standard (Vector Laboratories; Cat\# PK-6100). Samples were stained with 3,3'diaminobenzidine (DAB) and mounted after counterstaining with Mayer's hematoxylin. The photomicrographs were evaluated using Aperio ImageScope software (Aperio Technologies) and the percentage of the area affected by the color reaction was assessed using the standard software provided by the company.

\section{Skin grafting}

ROSA26-DsRed monomer-LEW Tg rats $\left(\mathrm{RT}^{1}{ }^{1}\right.$ ) $(\mathrm{n}=4)$ were used as donors and wild-type LEW rats $\left(\mathrm{RT} 1^{1}\right)$ as recipients $(\mathrm{n}=4)$ (Charles River, USA). Individual full-thickness skin grafts $(1 \mathrm{~cm}$ square) were prepared to fit a paired bed on the back (center) of isoflurane anesthetized recipients. The graft was secured with 8 (5/0 silk) interrupted sutures and then covered with dressings as required. Skin survival was assessed regularly using the following grading system: no evidence of rejection (0), graft fully edematous (1), less than $50 \%$ of the graft hemorrhagic or scabbed (2), more than $50 \%$ of the graft hemorrhagic or scabbed (3), graft fully rejected (4). Rejection was defined as a score of 2 or more. The grafts were inspected weekly up to 4 weeks post-graft and the results were recorded using a Sony Cyber-shot (DSC-TX1) camera. As controls, wild-type LEW rats $\left(\mathrm{RT} 1^{1}\right)(\mathrm{n}=4)$ were used as donors and wild-type LEW rats $\left(\mathrm{RT}^{1}{ }^{1}\right)$ $(n=4)$ as recipients (Charles River, USA). The same procedure and rejection assessment as been followed as previously described.
Heterotopic heart transplantation

All transplantations were performed using 8 week-old male rats. The heart from ROSA26-DsRed monomerLEW Tg rat $\left(\mathrm{RT}^{1}{ }^{1}\right)(\mathrm{n}=6)$ was transplanted heterotopically at the neck of a wild-type LEW rat $\left(\mathrm{RT} 1^{1}\right)$ according to a grafting method previously published (Heron 1971). Briefly, the aorta and superior vena cava of the donor heart were connected to the recipient's common carotid artery and jugular vein using Teflon cuffs (Terumo Medical Corporation, USA Cat\#. 3SR-OX2051CA and 3SR-OX1851CA), respectively. Cardiac graft rejection was defined as the day when the heart grafts stopped beating (Martins 2008). The transplanted animals were euthanized at different time points post echocardiographic analysis up to 6 months post-transplant.

\section{Echocardiographic imaging}

Transthoracic and neck echocardiographic imaging was performed by a blinded observer using a dedicated Vevo $^{\circledR} 2100$ System (21 MHz broadband sector transducer) (Visualsonics Inc., Toronto, ON, Canada located at STTARR, MaRS Building, TMDT). Echocardiography was performed at baseline (5 days prior transplant, in the donor animal) and at 10 days, 4 weeks, 6 weeks post-HHT and monthly up to 6-months time point (long term study). Rats ( $\mathrm{n}=3$ per group, 2 groups) were anesthetized using $2 \%$ isoflurane with oxygen. The LV end systolic dimension (LVESD) and end diastolic dimension (LVEDD) were obtained from M-mode tracings at the midpapillary level. The fractional shortening (FS) was calculated as follows: FS $(\%)=[($ LVEDD LVESD)/LVEDD] $\times 100$. We investigated the transplanted heart using M-mode for visualization and quantification of wall motion as well as Doppler Mode for detection of blood vessels, blood flow and valves activity.

Magnetic resonance imaging (MRI)

6 months after cell transplantation, cardiac MRI was performed on two animals $(n=2)$ transplanted with ROSA26-DsRed monomer-LEW Tg heart using a$7 \mathrm{~T}$ micro-MRI with surface coil signal reception. Specifics of acquisition are: $300-\mu$ isotropic resolution $(300 \times 300 \times 300 \mu)$ in $128 \times 128 \times 128 \quad 3 \mathrm{D}$ 
matrix, ungated 3D-ultra-short echo time technique (3D-UTE), 2 acquisitions with minimum TE (20- $\mu \mathrm{s})$ and $250 \mu \mathrm{s}, 18 \mathrm{~min} /$ acquisition. The electrocardiographic gating was optimized with two cardiogram electrodes attached to the animal's forelimbs with respiratory motion and body temperature monitors (Small Animal Instruments, Stony Brook, NY).

\section{Statistical analysis}

Quantitative data are expressed as mean \pm SEM. Statistical analysis was performed by one-way ANOVA, followed by Bonferroni multiple comparisons was used to compare groups at different timepoints (fractional shortening). A value of $p<0.05$ was considered statistically significant (Online Resource 1).

\section{Results}

Generation and breeding conditions of ROSA26DsRed monomer-LEW Tg rat lines

We generated four lines of ROSA26-DsRed monomer-LEW Tg rats $\left(\mathrm{RT}^{1}{ }^{1}\right)$. The murine ROSA promoter sequences used to target expression had been previously used in both $\mathrm{Tg}$ mice and rats (Kisseberth et al. 1999; Zambrowicz et al. 1997) to drive nearly ubiquitous expression of reporter genes. We expected a similar expression pattern for our ROSA26-DsRed monomer Tg rats. Transgene constructs were quantified, microinjected into rat eggs and surgically transferred to recipients. Tail biopsies from potential $\mathrm{Tg}$ rats were obtained 5 weeks after injecting eggs (3 weeks gestation time and 2 weeks of post-natal growth). Extraction of genomic DNA and RNA from tail biopsies was performed for quantitative real-time PCR (qPCR) and RT-PCR analysis to estimate the transgene copy number as well as expression of the inserted gene in $\mathrm{Tg}$ progenies. The lines with an obvious transgene were bred to transgene heterozygosity. Heterozygous rats for the $\mathrm{Tg}$ insert were viable, fertile and did not display obvious abnormalities associated with transgene insertion or expression. The homozygous condition remains to be elucidated. As there are multiple copy numbers of the injected expression construct, it is possible that the homozygous condition may result in infertility caused by unstable reproductive activity, lethality in embryonic stages, or premature growth in newborn animals as previously shown in several reports (Chang et al. 2013). We did not generate homozygous rats because our previous studies with $\mathrm{GFP}^{+} \mathrm{Tg}$ rats (Inoue et al. 2005) exhibited mortality of premature offspring due to organ failure of different degrees related to transgene toxicity. We typically maintained the line by breeding heterozygous $\mathrm{Tg}$ male rats, starting at approximately 8 weeks of age, to wild-type LEW females. However, the use of female $\mathrm{Tg}$ as breeders was also successful. We characterized the DsRed monomeric expression pattern in lines 7-10.

DsRed mono detected using Southern Blot, qPCR, RT-PCR, PCR and Western Blotting (WB)

We used quantitative real-time PCR to estimate DsRed transgene copy number in $\mathrm{Tg}$ lines. We demonstrated the reproducibility of copy number quantification with this method after Southern Blot analysis (Online Resource 2, Fig. S1A) and concluded that there was no variation in copy number across independent $\mathrm{Tg}$ lines. Almost all of the animals analyzed $(90 \%)$ contained 4 tandem copies of the DsRed transgene integrated at one genomic location (Online Resource 2, Table S1B).

Non-quantitative PCR of genomic DNA extracted from heart, lung, liver, kidney and spleen was used to determine both transgene random integration and integrity of the integration events; the presence of DsRed mono DNA sequence was confirmed in every organ (Online Resource S2, Fig. S1C). Non-quantitative PCR of genomic DNA extracted from rat-tail biopsies was used for routine genotyping (Fig. 1a).

Endogenous DsRed-synthesizing ability in $\mathrm{Tg}$ animals was tested by reverse transcription polymerase chain reaction (RT-PCR) (Fig. 1b). We found that mRNA containing the coding regions for DsRed was present in all the tested organs (heart, lung, liver, kidney and spleen) of Tg rats; organs from wild-type controls had no detectable levels.

Western blot analysis of the DsRed mono protein was used to confirm the Tg integration in the heart, lung, liver, kidney and spleen of Tg animals (Fig. 1c). Result showed that the DsRed mono protein is expressed in every organ and in bone marrow-derived mesenchymal stromal cells. 


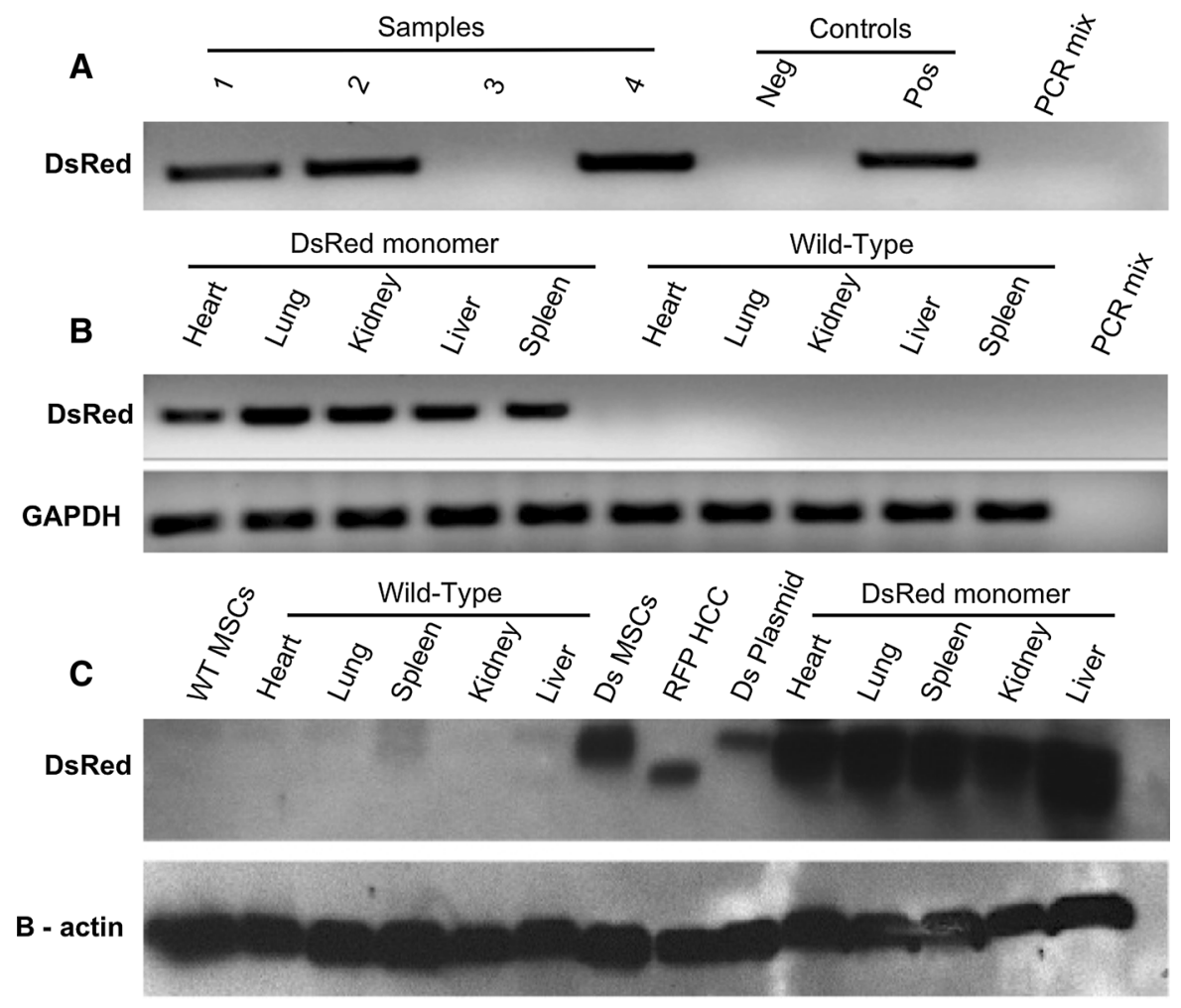

Fig. 1 Confirmation of the production of Tg DsRed gene and protein. Sequential isolation of RNA, DNA and protein from ROSA26-DsRed monomer-LEW Tg rat organs. All the experiments were performed $3 \times$, each with similar results. In $\mathbf{a}$ and $\mathbf{b}$, only DsRed DNA/cDNA was amplified by this method. GAPDH was used as an internal control. a Representative of PCR genotyping. Lanes 1, 2, and 4 represents DsRed positive progeny; lane 3 represents DsRed negative progeny; lanes 5 and 6 are wild-type and DsRed genomic DNA used as negative and positive control, respectively. b Presence of DsRed cDNA is confirmed in ROSA26-DsRed monomer-LEW Tg rat organs.

DsRed mono fluorescence in vivo and ex vivo

The DsRed fluorescent signal in hemizygous 5-daysold pups could be detected using an in vivo imaging system, and was clearly distinguishable from wildtype pups (Fig. 2a). No fluorescent signal could be detected in the hair of adult ROSA26-DsRed monomer-LEW Tg rats (data not shown). The fluorescence signal in each organ was detected by ex vivo imaging after organ collection from 21 days-old male rats (Fig. 2b). To evaluate signal intensities, regions of interest were selected over the mesh areas (background fluorescence and background from the imaging stage and plate), and the total fluorescence signal from those areas was determined as detailed described in
Lanes 1-5 are DsRed organs, lanes 6-10 are wild-type LEW rat organs $(\mathrm{n}=3)$. Lane 1, 6 heart; lane 2, 7 lung; lane 3, 8 kidney; lane 4, 9 liver; line 5, 10 spleen. $\mathbf{c}$ Representative of western blot analysis on DsRed positive organs. Western blotting using an anti-DsRed/RFP antibody $(35 \mathrm{kDa})$ and an anti-beta Actin antibody as internal control (45 kDa). Lane 1 wild-type BMderived MSCs (negative control); lanes 2-6 wild-type organs; lane 7 DsRed BM-derived MSCs (passage 4); lane 8 RFP positive human cervical carcinoma (Ab positive control); lane 9 transduced cells with a constitutively expressed DsRed-plasmid (Ef1a promoter), lanes 10-14 DsRed organs

methods section. In vivo and ex vivo fluorescence imaging showed that DsRed mono was expressed at uniform fluorescence intensity among organs.

Detection of the DsRed mono protein by IHC, IF and flow cytometry

In ROSA26-DsRed monomer-LEW Tg animals the marker gene was silenced stochastically, resulting in a mosaic expression pattern. The pattern, which comprise patches of a contiguously similar genotype, differs between organs but is similar in a given organ among animals (Fig. 3). DsRed mono protein was detected with horseradish peroxidase (HRP)/diaminobenzidine (DAB) staining. Computer-generated 

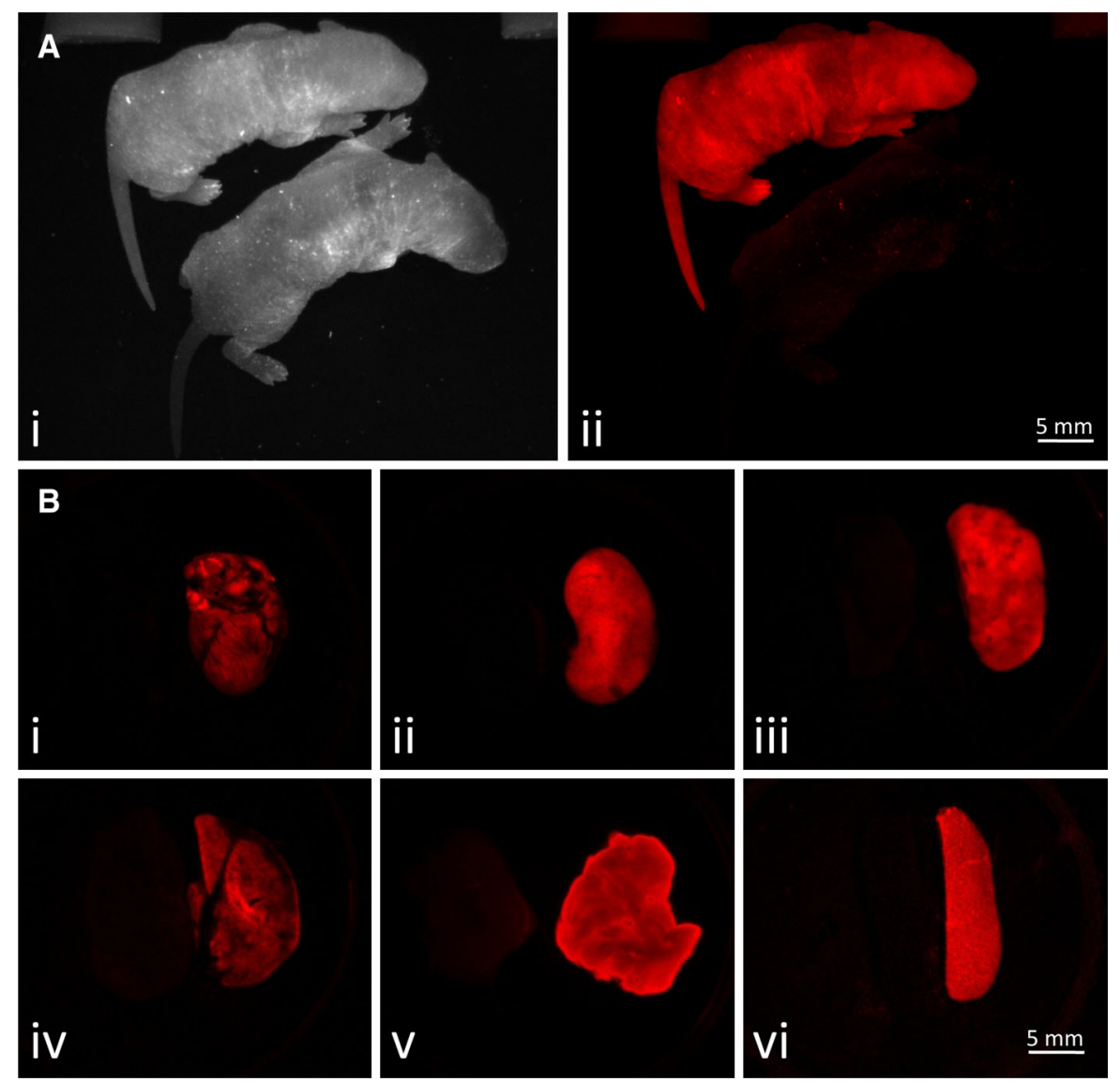

Fig. 2 DsRed fluorescent signal evaluated in vivo and ex vivo. Spectral fluorescence images were obtained using the Maestro $^{\mathrm{TM}}$ in vivo imaging system. Experiments were performed $3 \times$, each with similar results. Bar $5 \mathrm{~mm}$. a 5 days-old pups were examined under $\mathbf{i}$ visible and ii $558 \mathrm{~nm}$ excitation light.

quantitative image analysis of DsRed positive areas was compared with a standardized value (mean percentage) extrapolated from the wild-type organs stained in parallel. Liver tissue expressed $84.2 \pm$ $1.8 \%$; kidney, $71.4 \pm 5.2 \%$; and spleen $88.3 \pm$ $2.1 \%$ DsRed mono protein (Fig. 3a, $\mathrm{n}=5$ ). Heart tissue expressed $71.6 \pm 13.8 \%$ and lung, $77.8 \pm$ $3.2 \%$ (Online Resource S2). Flow cytometric analysis of freshly isolated organs $(77.9 \pm 3.4 \%$ in liver, $65.2 \pm 2.8 \%$ in kidney and $93.4 \pm 2.8 \%$ in spleen) confirmed the mosaic expression pattern of the DsRed protein (Fig. 3b, $\mathrm{n}=5$ ).

Using flow cytometric analysis, we demonstrated that intracellular staining performed with a FITC (Fluorescein isothiocyanate) labeled anti-RFP (red fluorescent protein) antibody did not enhance the b DsRed-expression pattern in representative organs: $\mathbf{i}$ heart, ii kidney, iii lung, iv liver, $\mathbf{v}$ pancreas, vi spleen were removed from a (left) LEW wild-type rat and (right) positive DsRed monomer-LEW Tg rat $(\mathrm{n}=3)$

DsRed mono detection signal on channels FL1 versus FL2 in organs (Online Resource S3) indicating that antibody detection was equivalent to protein fluorescence signaling.

Flow cytometric analysis of freshly isolated bone marrow indicated that $76.9 \pm 0.7 \%$ (Online Resource S4A), expressed DsRed mono, while in peripheral blood mononuclear cells (PBMCs) the percentage was lower: $28.5 \pm 2.5 \%$ in lymphocytes, $18.6 \pm 3.4 \%$ in neutrophils, and $30.2 \pm 4.5 \%$ in monocytes (Online Resource S4B).

DsRed mono Tg mesenchymal stromal cells (MSCs) exhibited the same morphologic and phenotypic properties as wild-type MSCs (Karaoz et al. 2009). The $\mathrm{Tg}$ cells were positive for CD49e $(68.4 \pm 16.0 \%)$, CD29 $(79.5 \pm 5.4 \%)$ and CD90 
Fig. 3 Differential DsRedexpression pattern between organs harvested from ROSA26-DsRed monomerLEW Tg rats.

a Representative staining of experiments performed $3 \times$, each with similar results. The photomicrographs were evaluated using Aperio ImageScope software and the percentage of the area affected by the color reaction was assessed, $\mathrm{n}=5$. Black bar $1 \mathrm{~mm}$, red bar $50 \mu$, black rectangle area at higher magnification in bottom left in each panel. b Representative flow cytometry of cells from positive organs. Freshly extracted, unstained cells from liver, kidney and spleen analyzed on FL2 channel $(n=5)$. (Color figure online)

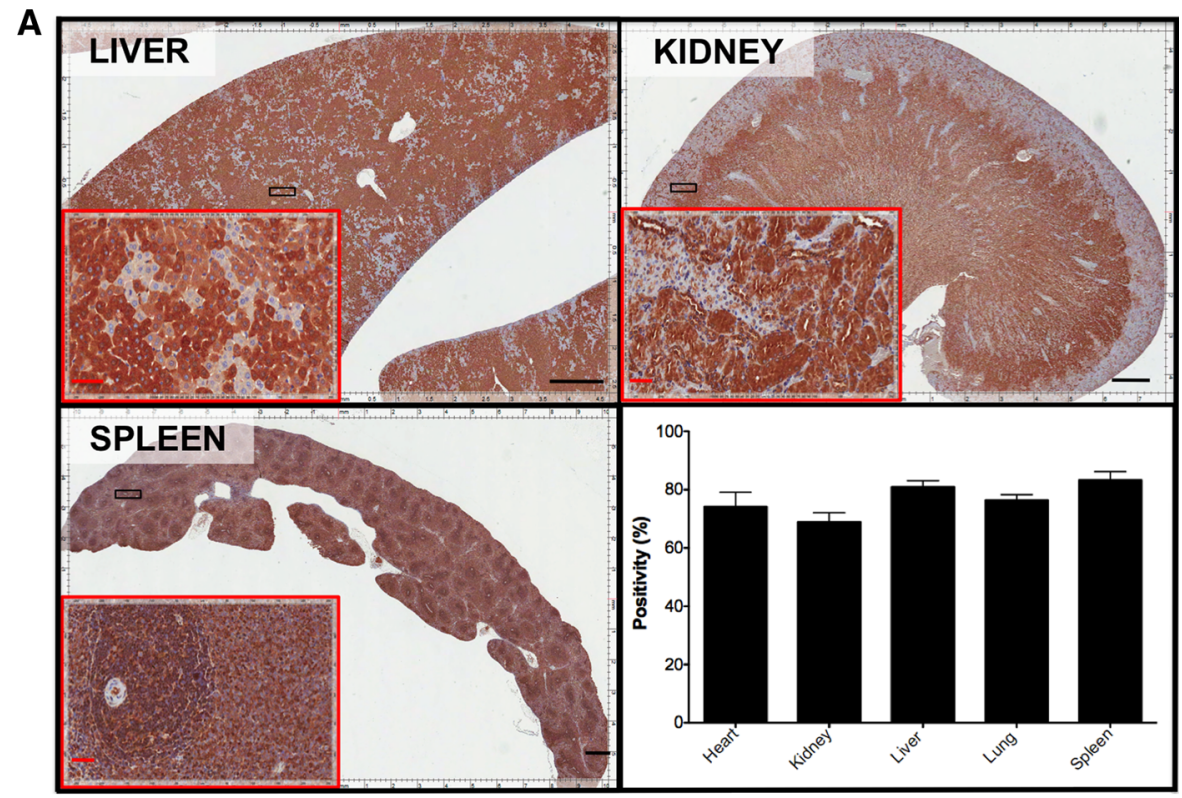

B

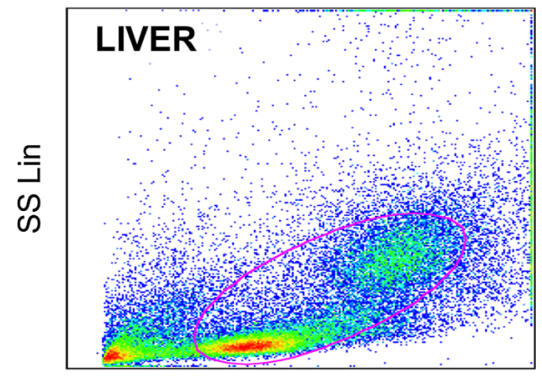

FS Lin

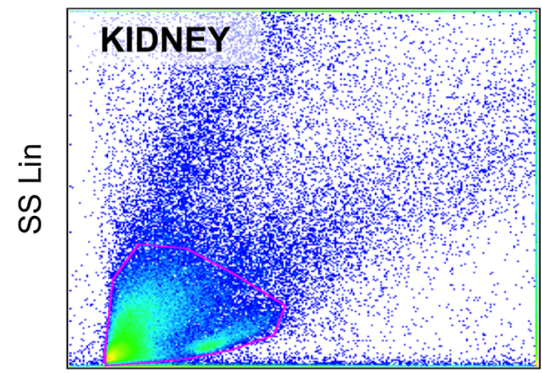

FS Lin

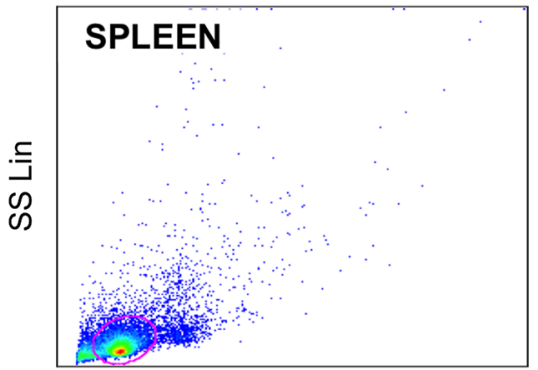

FS Lin

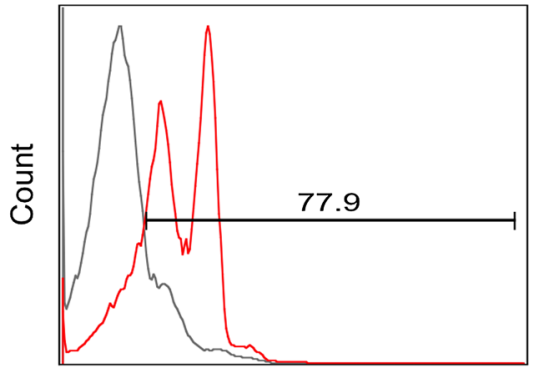

DsRed (FL2)

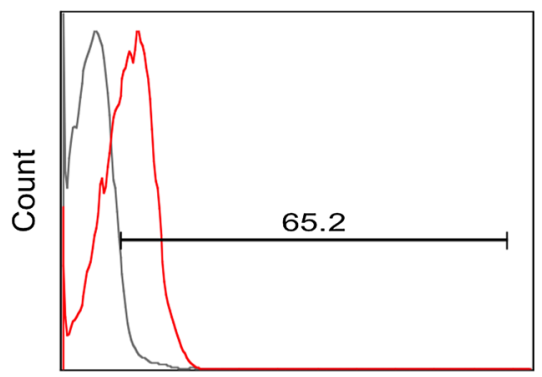

DsRed (FL2)

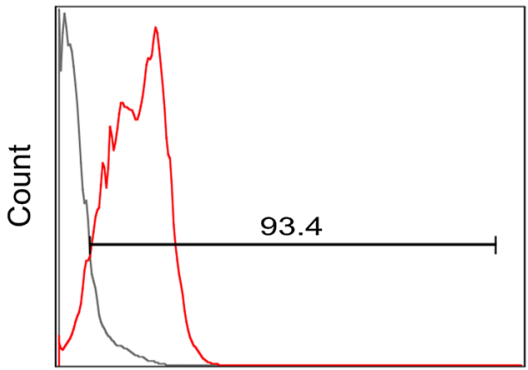

DsRed (FL2) 
$(80.9 \pm 9.6 \%)$ and negative for CD45 and for CD11b (Online Resource $\mathrm{S} 4 \mathrm{C}, \mathrm{n}=5$ ).

BM-MSCs at passage 4 were fixed and observed under fluorescence microscopy and showed that the cells expressed the fluorescent protein (Online Resource S5A). Finally, we determined the most efficient fixative solution and antibody staining for 4 and $10 \mu \mathrm{m}$ tissues (data not shown). DsRed mono organs fixed with acetone at room temperature are shown in Online Resource S5B.

Expression patterns of DsRed mono and relative percentages are summarized in Online Resource S6.

Transgenic skin grafting indicates that DsRed immunoreactivity caused inflammatory changes but no rejection

To test the in vivo immunogenicity of the DsRed rat tissue, we performed skin grafting by removing skin from the backs of ROSA26-DsRed monomer-LEW Tg rats and grafting onto a wound located on the backs of wild-type LEW rats. 7 days post-grafting, the dressing was removed and the Tg skin remained in place and appeared viable and vascularized (Fig. 4a, n=4). The observation was performed weekly for up to 4 weeks post transplant (Fig. $4 \mathrm{~b}, \mathrm{n}=4$ ). There was no significant difference in the survival of wild-type skin grafts $(p>0.05)$ versus Tg skin grafts (data not shown) suggesting that presence of the Tg protein did not result in acute rejection. The observation was made using two approaches: (i) visual inspection using a scale graded from 0 (no evidence of rejection) to 1 (graft fully edematous), and (ii) by weekly spectral fluorescence imaging, from week one (Fig. 4c) to week four (Fig. 4d). At week four, DsRed mono expression was detectable by fluorescence imaging, suggesting that the $\mathrm{Tg}$ protein was still being expressed.

Intense DsRed expression was detected in the epidermis (surface and follicular), sebaceous glands, and in occasional stromal cells (prominently mast cells) by immunohistochemical assay (Fig. 4h). The epidermis and adnexa in adjacent segments were negative for DsRed. Occasional stromal cells and collagen were positive within the host tissue. The marginal tissue (host/recipient) was negative for DsRed protein. There were rare multifocal DsRedpositive large cells within the stroma of the marginal host tissue (likely migrating dendritic cells from the allograft) (Fig. 4f). Intense focal staining was present within the dermal collagen (considered artifactual). As expected, no DsRed expression was detected in wildtype skin grafted onto wild-type recipients.

The grafted Tg skin was full-thickness by histological examination (Fig. 4e). Segmental lymphocytic and plasmacytic dermatitis was observed in the grafts, suggesting some degree of immunoreactivity. The inflammatory changes were associated with epidermal changes (vacuolar degeneration apoptosis of keratinocytes, and focal epidermal attenuation and crusting) indicating active inflammation related to the wound healing process. However, a large segment of the epidermis was intact, even hyperplastic (Fig. 4g). Specifically, the graft was infiltrated by moderate to large numbers of inflammatory cells (lymphocytes, plasma cells, unidentified mononuclear cells (monocytes), and low numbers of mast cells (Fig. 4i). The inflammation was more severe in subcutaneous muscle, within and around the hair follicles and sebaceous glands, and around dermal vasculature, suggestive of chronic-active, focal, severe inflammation. Such inflammation does not imply eventual rejection. It is documented that even syngeneic grafts could become infiltrated with mononuclear cells, and skin allografts may survive such an infiltrate (Youssef et al. 2002). In wild-type to wild-type skin grafts, there was no dermatitis and the epithelium was normal. The focal inflammation within the panniculus was likely against host hair material dislodged or displaced during surgery, indicative of chronic-active, focal, mild inflammation (Online Resource S7).

Morphological and functional aspect of long-term heterotopic heart transplants using magnetic resonance imaging (MRI) and echocardiography

To determine whether transplantation of ROSA26DsRed monomer-LEW Tg hearts affected function, rat hearts were assessed at different time points by echocardiography (Fig. 5a). Left ventricular function was evaluated by echocardiography at baseline, 4 weeks, 6 weeks and monthly (up to 6 months) postoperatively. In the wild-type group, recovery of heart function (evaluated as percentage of fractional shortening of the transplanted heart from baseline) occurred after 3 months (10 days, $p<0.0001$; 4 weeks, $p<0.0001$; 6 weeks, $p<0.001$ ), while in the Tg DsRed/wild-type group, a significantly lower 


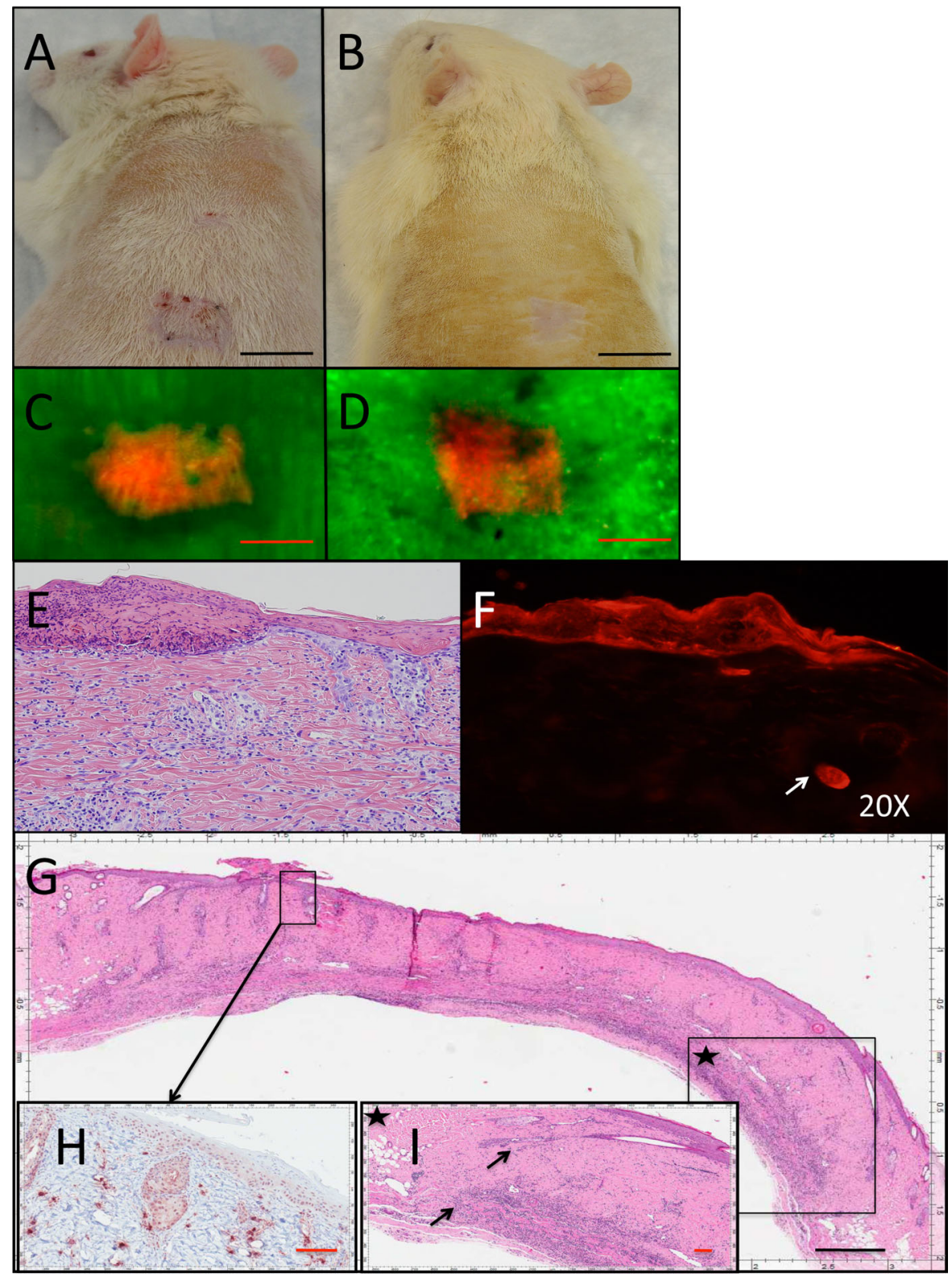

Fig. 4 Evaluation of wild-type LEW rats grafted with fullthickness skin grafts from ROSA26-DsRed monomer-LEW. a Skin graft at week one and $\mathbf{b}$ week four, visual evaluation. Bar $1 \mathrm{~cm}, \mathrm{n}=4$. Spectral fluorescence images obtained using the Maestro ${ }^{\mathrm{TM}}$ in vivo imaging system at $\mathbf{c}$ week one and $\mathbf{d}$ week four post graft. Bar $500 \mu$. e Photomicrographs of hematoxylin and eosin-stained full thickness syngeneic skin graft. Crosssections, $\times 20$ magnification. $\mathbf{f}$ The occasional DsRed positive cells deep within the host tissue are likely migrating dendritic

fractional shortening was documented over a 6 month period (Fig. 5b). Transplanted animals receiving a $\mathrm{Tg}$ heart showed a significant difference in fractional cells from the grafted skin (arrow). Cross-sections, Zeiss AxioObserver, Cy3 Filter Set, $\times 20$ magnification. g The graft is infiltrated by inflammatory cells. Bar $500 \mu$. Arrow area in h. Star area in i. h Within the graft most of the epidemis, adnexal structures, and occasional large stromal cells express DsRed protein. Red bar $100 \mu$. i Individual and clusters of lymphocytes (arrows) are also present at dermo-epidermal junction. Red bar $100 \mu$. (Color figure online)

shortening at 6 weeks $(p<0.001), 3$ months $(p<0.0001), 5$ months $(p<0.001)$ and 6 months post-transplant $(p<0.05)$ compared with baseline. 


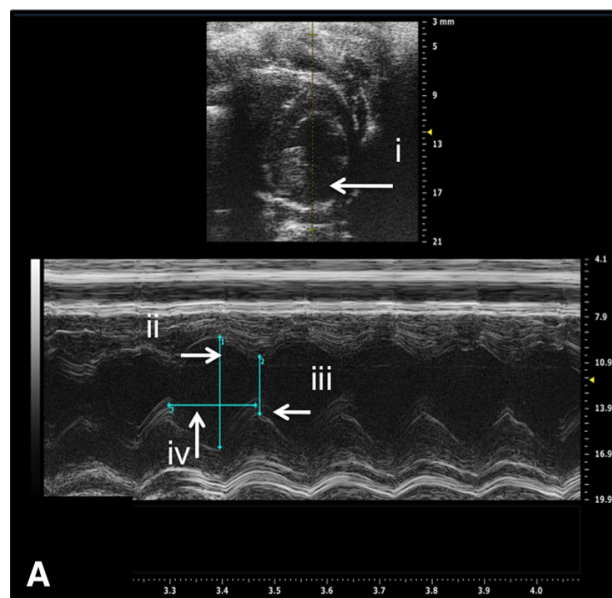

Fig. 5 Cardiac function assessed by echocardiography. A representative M-mode echocardiography recorded to calculate fractional shortening (FS) in the rat. Measurements done $i$ at the papillary muscle level, $i i$ Left ventricular end-diastolic dimension (LVEDD), iii Left ventricular end-systolic dimension

The lower recovery is likely due to inflammatory processes mediated by the DsRed protein (Fig. 5b, $\mathrm{n}=5)$.

These findings were confirmed by Doppler echocardiographic analysis (Online Resource S8A-S8D) and cardiac MRI (Online Resource -S8F), which noninvasively evaluate the viability of the transplanted organ and can assess heart function and structures 6 months post-transplantation. Echocardiographic Doppler analysis enabled cardiac wall motion to be observed and confirmed the absence of blood flow within both ventricles. Cardiac MRI provided detailed images of the heart and blood vessels from many views. The scans confirmed heart motion, the presence of heart remodeling due to the transplant model and the presence of an organized thrombus in the right ventricle. The cardiac studies, like the skin grafting, showed evidence of inflammation but lack of rejection. Our data indicate that presence of Tg DsRed protein affected function of the transplanted organ, probably from an inflammatory response to the graft.

\section{Discussion}

The increasing prevalence of clinical organ transplantation has highlighted the need to develop better experimental animal models. Due to its larger size, the

\section{HHT TRANSPLANT MODEL}

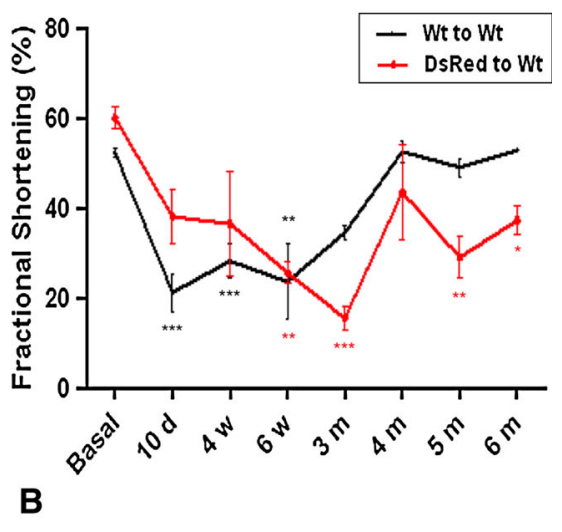

(LVESD), iv cardiac cycle. b Representative of FS of the cervical DsRed mono/WT transplanted heart at baseline, 10 days, 4 weeks, 6 weeks and monthly (up to 6 months) using M-mode into WT recipients $(\mathrm{n}=5)(* p<0.05$; $* * p<0.001$; $* * * p<0.0001)$

rat model may be more suited for studying surgical interventions than mouse models (Davis et al. 2012).

In this study, we established and characterized an inbred Tg LEW rat with DsRed monomeric (DsRed mono) protein as a fluorochrome and evaluated the ability of DsRed mono Tg rats to serve as a model for cell tracking studies, and organ transplantation.

The Tg animals bred normally, were of equal size, had normal litter sizes, behaved similarly to LEW wild-type rats and exhibited no lethality that correlated with the presence of the transgene. We observed single copy integrants in the genome of almost all of the DsRed mono animals. Analyses of DsRed expression over many generations in the line revealed that the pattern and intensity of transgene expression was stable. No variation of fluorescence intensity was observed either among individual rats of the same progeny or between genders.

A $\mathrm{Tg}$ rat carrying an alternative fluorochrome to GFP, DsRed2 and Luciferase was developed to complement existing models. The Tg DsRed rat model is suitable for studying a specific organ; in fact, Alb-DsRed2 Tg rats (Sato et al. 2003) are exclusively used to investigate in vivo liver regeneration. The rat model in our study however, has greater novelty and utility because the DsRed fluorescent protein is ubiquitously expressed under the control of the ROSA26 promoter. 
DsRed mono cells were detected in all organs (including the heart, kidney, liver, lung, and spleen) and skin, with the exception of hair. While the expression is high in bone marrow cells and MSCs, levels were low in peripheral blood mononucleated cells. This observation should be taken into account by investigators interested in tracking inflammatory cells with this model.

A mosaic pattern of fluorescent protein expression was detected in all organs, and is likely the result of an interaction between the transgene insertion site and epigenetic regulation by yet poorly understood mechanisms (Lao et al. 2012). In some cases, Tg animals derived from plasmid DNA microinjection are subject to complete silencing of the transgene as well as by changes in promoter expression (Karpen 1994; Grieshammer et al. 1995). Silencing of transgene expression depends on the location of transgene insertion (heterochromatin is usually higher than euchromatin) (Kioussis and Festenstein 1997), the degree of transgene methylation and the genetic background (Hofmann et al. 2006; Khokha et al. 1994).

Further studies are needed to define whether the promoter or different chromosomal insertion sites result in epigenetic regulation and silencing in $\mathrm{Tg}$ animals (Day et al. 2000; Tang et al. 2001). Mosaic DsRed expression levels in cells of the same organ may be explained by variable epigenetic regulation. For example, medulla kidney cells express DsRed whereas cells of the kidney cortex are negative.

Additional advantages of DsRed mono $\mathrm{Tg}$ rats include protein visualization by immunohistochemistry, fluorescence microscopy, flow cytometric analysis and the lack of interference from autofluorescence (Cotlet et al. 2001; Gross et al. 2000). A red fluorescent signal was detectable in organs and cells of ROSA26-DsRed monomer-LEW Tg rats while control wild-type organs and cells had no detectable levels of fluorescence at the optimal excitation and emission wavelengths for the DsRed mono fluorochrome (Sacchetti et al. 2002). The fluorescent protein is bright enough to provide sufficient signal above autofluorescence to be reliably detected and imaged. Further, DsRed mono presents sufficient photostability to be imaged for the duration of the experiment.

In this study, we also showed that MSCs derived from the bone marrow of DsRed mono Tg rats, not only expressed high levels of DsRed protein, but also exhibited the same morphologic and phenotypic properties as wild-type MSCs, suggesting that DsRed mono MSCs may be a useful tool in studying MSC migration, functionality and biodistribution in vivo while avoiding confounding autofluorescence.

To test immunoreactivity to DsRed mono protein, we successfully performed skin grafting and heterotopic heart transplantations with $\mathrm{Tg}$ rats as donors into LEW wild-type rat recipients. It has become increasingly clear that the transfer of cells or organs expressing a reporter molecule into immunocompetent hosts triggers an immune response directed against the Tg cells (Kulbatski et al. 2007). Immune responses to GFP positive cells and tissues have been reported in several studies (Stripecke et al. 1999; Gambotto et al. 2000). This is the first report of organ transplantation with DsRed mono $\mathrm{Tg}$ rats showing that: (i) Tg grafted skin emitted fluorescence in vivo 4 weeks after grafting indicating that the protein was bioactive at this time point; (ii) transplanted hearts from ROSA26-DsRed monomer-LEW Tg rats were observed without any immunosuppressive agents for up to 6 months; (iii) heterotopically transplanted hearts were beating and expressed DsRed protein during this time. The skin grafting and heart transplant experiments support the finding that DsRed mono transplanted cells and organs induce only moderate immune responses that do not result in graft rejection. For this reason, DsRed mono $\mathrm{Tg}$ rats acquire a remarkable value in the research field.

In summary, the ROSA26-DsRed monomer-LEW Tg rat represents a new and useful $\mathrm{Tg}$ animal model for cell transfer studies or cell trafficking analysis in regenerative medicine and transplantation research because it overcomes several issues presented by existing Tg models. DsRed mono fluorescent protein is stably expressed at high levels and in different cell types and can be unequivocally identified and tracked. Also, DsRed mono Tg rats carry a low-immunogenic fluorescent marker protein, enabling cell therapy studies and long-term analysis of transplantation models to be performed.

Acknowledgments We are grateful to Dr. Yoko Kosaka for assistance with Flow cytometric analysis and to Mr. Kikuchi and Dr. He for training S. Montanari in microsurgery. We also thank Dr. Takashi Murakami for assistance in Southern Blot design. This research was supported by the Orsino Translational Research Laboratory at Princess Margaret Hospital and by the Gloria and Seymour Epstein Chair in Cell Therapy and Transplantation at University Health Network and the University of Toronto to AK. 
Conflict of interest No competing financial interests exist for any of the authors.

\section{References}

Baird GS, Zacharias DA, Tsien RY (2000) Biochemistry, mutagenesis, and oligomerization of DsRed, a red fluorescent protein from coral. Proc Natl Acad Sci U S A 97(22):11984-11989. doi:10.1073/pnas.97.22.11984

Bevis BJ, Glick BS (2002) Rapidly maturing variants of the Discosoma red fluorescent protein (DsRed). Nat Biotechnol 20(1):83-87. doi:10.1038/nbt0102-83

Campbell RE, Tour O, Palmer AE, Steinbach PA, Baird GS, Zacharias DA, Tsien RY (2002) A monomeric red fluorescent protein. Proc Natl Acad Sci U S A 99(12):7877-7882. doi:10.1073/pnas.082243699

Cerkovnik P, Perhavec A, Zgajnar J, Novakovic S (2007) Optimization of an RNA isolation procedure from plasma samples. Int J Mol Med 20(3):293-300

Chang SP, Opsahl ML, Whitelaw CB, Morley SD, West JD (2013) Relative transgene expression frequencies in homozygous versus hemizygous transgenic mice. Transgenic Res. doi:10.1007/s11248-013-9732-5

Conradi L, Pahrmann C, Schmidt S, Deuse T, Hansen A, Eder A, Reichenspurner H, Robbins RC, Eschenhagen T, Schrepfer S (2011) Bioluminescence imaging for assessment of immune responses following implantation of engineered heart tissue (EHT). J Vis Exp (JoVE) (52). doi:10.3791/ 2605

Cotlet M, Hofkens J, Habuchi S, Dirix G, Van Guyse M, Michiels J, Vanderleyden J, De Schryver FC (2001) Identification of different emitting species in the red fluorescent protein DsRed by means of ensemble and single-molecule spectroscopy. Proc Natl Acad Sci U S A 98(25): 14398-14403. doi:10.1073/pnas.251532698

Cozzi J, Fraichard A, Thiam K (2008) Use of genetically modified rat models for translational medicine. Drug Discov Today 13(11-12):488-494. doi:10.1016/j.drudis. 2008. 03.021

Davis J, Maillet M, Miano JM, Molkentin JD (2012) Lost in transgenesis: a user's guide for genetically manipulating the mouse in cardiac research. Circ Res 111(6):761-777. doi:10.1161/CIRCRESAHA.111.262717

Day CD, Lee E, Kobayashi J, Holappa LD, Albert H, Ow DW (2000) Transgene integration into the same chromosome location can produce alleles that express at a predictable level, or alleles that are differentially silenced. Genes Dev 14(22):2869-2880

Doyle A, McGarry MP, Lee NA, Lee JJ (2012) The construction of transgenic and gene knockout/knockin mouse models of human disease. Transgenic Res 21(2):327-349. doi:10. 1007/s11248-011-9537-3

Filipiak WE, Saunders TL (2006) Advances in transgenic rat production. Transgenic Res 15(6):673-686. doi:10.1007/ s11248-006-9002-x

Gama Sosa MA, De Gasperi R, Elder GA (2010) Animal transgenesis: an overview. Brain Struct Funct 214(2-3):91-109. doi:10.1007/s00429-009-0230-8
Gambotto A, Dworacki G, Cicinnati V, Kenniston T, Steitz J, Tuting T, Robbins PD, DeLeo AB (2000) Immunogenicity of enhanced green fluorescent protein (EGFP) in BALB/c mice: identification of an $\mathrm{H} 2-\mathrm{Kd}$-restricted CTL epitope. Gene Ther 7(23):2036-2040

Garcia-Parajo MF, Koopman M, van Dijk EM, Subramaniam V, van Hulst NF (2001) The nature of fluorescence emission in the red fluorescent protein DsRed, revealed by singlemolecule detection. Proc Natl Acad Sci U S A 98(25):14392-14397. doi:10.1073/pnas.251525598

Goulding AM, Rahimi Y, Shrestha S, Deo SK (2008) Dual function labeling of biomolecules based on DsRedMonomer. Bioconjug Chem 19(11):2113-2119. doi:10. 1021/bc800147k

Grieshammer U, McGrew MJ, Rosenthal N (1995) Role of methylation in maintenance of positionally restricted transgene expression in developing muscle. Development (Cambridge, England) 121(7):2245-2253

Gross LA, Baird GS, Hoffman RC, Baldridge KK, Tsien RY (2000) The structure of the chromophore within DsRed, a red fluorescent protein from coral. Proc Natl Acad Sci U S A 97(22):11990-11995. doi:10.1073/pnas.97.22.11990

Hakamata Y, Tahara K, Uchida H, Sakuma Y, Nakamura M, Kume A, Murakami T, Takahashi M, Takahashi R, Hirabayashi M, Ueda M, Miyoshi I, Kasai N, Kobayashi E (2001) Green fluorescent protein-transgenic rat: a tool for organ transplantation research. Biochem Biophys Res Commun 286(4):779-785. doi:10.1006/bbrc.2001.5452

Hakamata Y, Murakami T, Kobayashi E (2006) "Firefly rats" as an organ/cellular source for long-term in vivo bioluminescent imaging. Transplantation 81(8):1179-1184. doi:10.1097/01.tp.0000203137.06587.4a

Hara M, Murakami T, Kobayashi E (2008) In vivo bioimaging using photogenic rats: fate of injected bone marrowderived mesenchymal stromal cells. J Autoimmun 30(3):163-171. doi:10.1016/j.jaut.2007.12.007

Heron I (1971) A technique for accessory cervical heart transplantation in rabbits and rats. Acta Pathol Microbiol Scand Sect A Pathol 79(4):366-372

Hofmann A, Kessler B, Ewerling S, Kabermann A, Brem G, Wolf E, Pfeifer A (2006) Epigenetic regulation of lentiviral transgene vectors in a large animal model. Mol Ther J Am Soc Gene Ther 13(1):59-66. doi:10.1016/j.ymthe.2005.07. 685

Hung CJ, Yao CL, Cheng FC, Wu ML, Wang TH, Hwang SM (2010) Establishment of immortalized mesenchymal stromal cells with red fluorescence protein expression for in vivo transplantation and tracing in the rat model with traumatic brain injury. Cytotherapy 12(4):455-465. doi:10. 3109/14653240903555827

Inoue H, Ohsawa I, Murakami T, Kimura A, Hakamata Y, Sato Y, Kaneko T, Takahashi M, Okada T, Ozawa K, Francis J, Leone P, Kobayashi E (2005) Development of new inbred transgenic strains of rats with LacZ or GFP. Biochem Biophys Res Commun 329(1):288-295. doi:10.1016/j. bbrc.2005.01.132

Karaoz E, Aksoy A, Ayhan S, Sariboyaci AE, Kaymaz F, Kasap M (2009) Characterization of mesenchymal stem cells from rat bone marrow: ultrastructural properties, differentiation potential and immunophenotypic markers. Histochem Cell Biol 132(5):533-546. doi:10.1007/s00418-009-0629-6 
Karpen GH (1994) Position-effect variegation and the new biology of heterochromatin. Curr Opin Genet Dev 4(2):281-291

Khokha MK, Landini G, Iannaccone PM (1994) Fractal geometry in rat chimeras demonstrates that a repetitive cell division program may generate liver parenchyma. Dev Biol 165(2):545-555. doi:10.1006/dbio.1994.1274

Kioussis D, Festenstein R (1997) Locus control regions: overcoming heterochromatin-induced gene inactivation in mammals. Curr Opin Genet Dev 7(5):614-619

Kisseberth WC, Brettingen NT, Lohse JK, Sandgren EP (1999) Ubiquitous expression of marker transgenes in mice and rats. Dev Biol 214(1):128-138. doi:10.1006/dbio.1999. 9417

Kulbatski I, Mothe AJ, Keating A, Hakamata Y, Kobayashi E, Tator CH (2007) Oligodendrocytes and radial glia derived from adult rat spinal cord progenitors: morphological and immunocytochemical characterization. J Histochem Cytochem 55(3):209-222. doi:10.1369/jhc.6A7020.2006

Lao Z, Raju GP, Bai CB, Joyner AL (2012) MASTR: a technique for mosaic mutant analysis with spatial and temporal control of recombination using conditional floxed alleles in mice. Cell Rep 2(2):386-396. doi:10.1016/j.celrep.2012. 07.004

Martins PN (2008) Assessment of graft function in rodent models of heart transplantation. Microsurgery 28(7): 565-570. doi:10.1002/micr.20544

Mashimo T, Serikawa T (2009) Rat resources in biomedical research. Curr Pharm Biotechnol 10(2):214-220

Menoret S, Remy S, Usal C, Tesson L, Anegon I (2010) Generation of transgenic rats by microinjection of short DNA fragments. Methods Mol Biol (Clifton, NJ) 597:81-92. doi:10.1007/978-1-60327-389-3_6

Moloney TC, Dockery P, Windebank AJ, Barry FP, Howard L, Dowd E (2010) Survival and immunogenicity of mesenchymal stem cells from the green fluorescent protein transgenic rat in the adult rat brain. Neurorehabil Neural Repair 24(7):645-656. doi:10.1177/1545968309357745

Mothe AJ, Kulbatski I, van Bendegem RL, Lee L, Kobayashi E, Keating A, Tator CH (2005) Analysis of green fluorescent protein expression in transgenic rats for tracking transplanted neural stem/progenitor cells. J Histochem Cytochem 53(10):1215-1226. doi:10.1369/jhc.5A6639.2005

Murakami T, Kobayashi E (2005) Color-engineered rats and luminescent LacZ imaging: a new platform to visualize biological processes. J Biomed Opt 10(4):41204. doi:10. 1117/1.2007947

Murakami T, Kobayashi E (2012) GFP-transgenic animals for in vivo imaging: rats, rabbits, and pigs. Methods Mol Biol (Clifton, NJ) 872:177-189. doi:10.1007/978-1-61779-7972_12

Pan XC, Deng YB, Sugawara Y, Makuuchi M, Okabe M, Ochiya T, Sugiura W, Kitazawa Y, Fuji N, Li XK, Miyamoto M, Kimura H (2009) Immunological behavior of enhanced green fluorescent protein (EGFP) as a minor histocompatibility antigen with a special reference to skin isograft and specific regulation of local graft-versus-host reaction (GvHR). Immunol Lett 123(2):103-113. doi:10. 1016/j.imlet.2009.02.004
Remy S, Tesson L, Usal C, Menoret S, Bonnamain V, NerriereDaguin V, Rossignol J, Boyer C, Nguyen TH, Naveilhan P, Lescaudron L, Anegon I (2010) New lines of GFP transgenic rats relevant for regenerative medicine and gene therapy. Transgenic Res 19(5):745-763. doi:10.1007/ s11248-009-9352-2

Sacchetti A, Subramaniam V, Jovin TM, Alberti S (2002) Oligomerization of DsRed is required for the generation of a functional red fluorescent chromophore. FEBS Lett 525(1-3):13-19

Sato Y, Igarashi Y, Hakamata Y, Murakami T, Kaneko T, Takahashi M, Seo N, Kobayashi E (2003) Establishment of Alb-DsRed2 transgenic rat for liver regeneration research. Biochem Biophys Res Commun 311(2):478-481

Sato Y, Endo H, Ajiki T, Hakamata Y, Okada T, Murakami T, Kobayashi E (2004) Establishment of Cre/LoxP recombination system in transgenic rats. Biochem Biophys Res Commun 319(4):1197-1202. doi:10.1016/j.bbrc.2004.04. 204

Shaner NC, Steinbach PA, Tsien RY (2005) A guide to choosing fluorescent proteins. Nat Methods 2(12):905-909. doi:10. 1038/nmeth819

Strack RL, Strongin DE, Bhattacharyya D, Tao W, Berman A, Broxmeyer HE, Keenan RJ, Glick BS (2008) A noncytotoxic DsRed variant for whole-cell labeling. Nat Methods 5(11):955-957. doi:10.1038/nmeth.1264

Strack RL, Hein B, Bhattacharyya D, Hell SW, Keenan RJ, Glick BS (2009) A rapidly maturing far-red derivative of DsRed-Express2 for whole-cell labeling. Biochemistry 48(35):8279-8281. doi:10.1021/bi900870u

Stripecke R, Carmen Villacres M, Skelton D, Satake N, Halene S, Kohn D (1999) Immune response to green fluorescent protein: implications for gene therapy. Gene Ther 6(7):1305-1312

Tang W, Luo XY, Sanmuels V (2001) Gene silencing: doublestranded RNA mediated mRNA degradation and gene inactivation. Cell Res 11(3):181-186. doi:10.1038/sj.cr. 7290084

Verkhusha VV, Akovbian NA, Efremenko EN, Varfolomeyev SD, Vrzheshch PV (2001) Kinetic analysis of maturation and denaturation of DsRed, a coral-derived red fluorescent protein. Biochemistry (Biokhimiia) 66(12):1342-1351

Wall MA, Socolich M, Ranganathan R (2000) The structural basis for red fluorescence in the tetrameric GFP homolog DsRed. Nat Struct Biol 7(12):1133-1138. doi:10.1038/ 81992

Youssef AR, Otley C, Mathieson PW, Smith RM (2002) Effector mechanisms in murine allograft rejection: comparison of skin and heart grafts in fully allogeneic and minor histocompatibility antigen-mismatched strain combinations. Transpl Int 15(6):302-309. doi:10.1007/s00147002-0407-z

Zambrowicz BP, Imamoto A, Fiering S, Herzenberg LA, Kerr WG, Soriano P (1997) Disruption of overlapping transcripts in the ROSA beta geo 26 gene trap strain leads to widespread expression of beta-galactosidase in mouse embryos and hematopoietic cells. Proc Natl Acad Sci U S A 94(8):3789-3794 